\title{
"The role of commodities investments in the decumulation phase of retirement"
}

\begin{tabular}{|c|c|}
\hline AUTHORS & $\begin{array}{l}\text { John Hua Fan } \\
\text { Osei K. Wiafe }\end{array}$ \\
\hline ARTICLE INFO & $\begin{array}{l}\text { John Hua Fan and Osei K. Wiafe (2016). The role of commodities investments in } \\
\text { the decumulation phase of retirement. Investment Management and Financial } \\
\text { Innovations, 13(3-2), 322-327. doi:10.21511/imfi.13(3-2).2016.04 }\end{array}$ \\
\hline DOI & http://dx.doi.org/10.21511/imfi.13(3-2).2016.04 \\
\hline RELEASED ON & Monday, 10 October 2016 \\
\hline JOURNAL & "Investment Management and Financial Innovations" \\
\hline FOUNDER & LLC "Consulting Publishing Company "Business Perspectives" \\
\hline & $\begin{array}{l}-=- \\
z=- \\
z=-\end{array}$ \\
\hline NUMBER OF REFERENCES & NUMBER OF FIGURES \\
\hline
\end{tabular}

(C) The author(s) 2022. This publication is an open access article. 
John Hua Fan (Australia), Osei K. Wiafe (Australia)

\title{
The role of commodities investments in the decumulation phase of retirement
}

\begin{abstract}
This paper examines the role of commodity-related investments in the decumulation phase of retirement. Benchmarked against a balanced portfolio, the findings suggest that including commodities in a traditional portfolio improves the retirement outcomes at the lowest percentiles of wealth distribution. Furthermore, we demonstrate that downside protection is more pronounced by reducing allocation to equities (rather than bonds) to invest in alternatives. An equally weighted combination of passive and active commodity-related investments provides superior downside protection compared to a traditional portfolio at all levels of allocations used in the analysis. As a consequence, commodities may be employed as a portfolio diversification tool particularly in the decumulation phase of retirement.
\end{abstract}

Keywords: alternatives, commodities, life cycle, superannuation, retirement.

JEL Classification: G11, G23.

\section{Introduction}

This paper examines the role of commodity-related investments in the decumulation phase of the retirement portfolio. Using a 20-year investment horizon and a 4 per cent drawdown rule, we investigate retiree's retirement outcome based on the investment strategy she chooses at retirement. Benchmarked against the traditional 60/40 asset allocation, we examine the performance of commodities long-only investment (S\&P-GSCI), active commodity-related trend following (Commodity Trading Advisors, CTAs/Managed Futures) and a combination of passive and active commodities-related investments. Our findings suggest that, compared to a traditional asset allocation, a strategy with allocations to commodityrelated investments significantly improves retirement outcomes. This is, particularly, the case at the lowest percentiles of wealth distribution.

Wiafe (2015) finds that whilst increasing stock levels of portfolios significantly increases the wealth outcome for the right tail of the distribution, it increases the chance of portfolio ruin which results from the overreliance on positive returns from volatile assets. In this paper, we argue that mean and median of the terminal wealth are inappropriate metrics for the measurement of retirement adequacy. As financial risk aversion is highest in pension relative to other types of investments (see Van Rooij et al., 2007), we posit that studies should focus on improving the worst outcomes (extreme

(c) John Hua Fan, Osei K. Wiafe, 2016.

John Hua Fan (Corresponding author), Ph.D., Department of Accounting, Finance and Economics, Griffith Business School, Griffith University, Australia.

Osei K. Wiafe, Ph.D., Griffith Centre for Personal Finance and Superannuation, Griffith Business School, Griffith University, Australia.

We thank Anup Basu, Robert Bianchi, Kevin Davis, Michael Drew, Eduardo Roca and Adam Walk for helpful comments. We acknowledge financial support from the Griffith Centre for Personal Finance and Superannuation (GCPFS), Griffith University. left tail of the distribution) instead. Therefore, commodity-related investments are selected as the focus, given their well-received advantage for portfolio diversification (Bodie and Rosansky, 1980; Anson, 1999; Jensen et al., 2002; Erb and Harvey, 2006; Gorton and Rouwenhorst, 2006). Hoevenaars et al. (2008) examine the role of commodities longonly investments in the accumulation phase of retirement. They find that alternative asset classes add value for long-term investors. For the first time in the pension literature, we examine the performance of commodity-related investments, both long-only and active trading, in the decumulation phase.

This paper presents three major contributions to the literature. First, we demonstrate that individuals have better downside protection (at the left tail of the distribution) during the decumulation phase by including commodity-related investments in their portfolios. At the $1^{\text {st }}$ percentile, increasing allocation to commodities up to 15 per cent increases terminal wealth. Even at 20 per cent, the $1^{\text {st }}$ percentile of terminal wealth is higher for the portfolio with alternatives than the traditional portfolio. At the $5^{\text {th }}$ percentile of terminal wealth, considerable difference exists in portfolio outcomes for the different strategies analysed. While increasing allocation to commodities generally decreases wealth at the $5^{\text {th }}$ percentile, the inverse is reported for the CTA/Managed Futures allocation.

Second, at both the $1^{\text {st }}$ and $5^{\text {th }}$ percentiles of the wealth distribution, our findings suggest that the downside protection is more pronounced by reducing allocation to equities (rather than bonds) to invest in commodity-related alternatives. This is explained by the high negative correlation between commodity-related alternatives and bonds, which is significantly higher than the correlation relative to equities. At the $1^{\text {st }}$ percentile, even when allocation to alternatives is increased with a reduction in bonds, there is still a significant increase in wealth 
levels with increasing allocation to CTA/Managed Futures, while the inverse is noted for allocation to commodities.

Finally, an equally weighted combination of the two commodity-related investments (long-only commodities and CTA/Managed Futures) provides superior downside protection compared to a traditional portfolio at all levels of allocations used in the analysis. These findings suggest that diversifying through alternative investments, indeed, provides better outcomes compared to the traditional portfolio in the decumulation phase of the retirement. This is, particularly, the case at the $1^{\text {st }}$ percentile, when downside protection is required the most.

For robustness, we investigate the worst outcomes for different allocation strategies by employing the Expected Tail Loss (ETL) and Value-at-Risk (VaR) metrics. We find that VaR and ETL generally decrease with increasing investment horizon. After 20 years in retirement, retiree $\mathrm{VaR}$ is, on average, lowest for a strategy with an allocation to CTA/Managed Futures. The strategy with a combination of alternatives however underperforms the remaining strategies, having the highest $\mathrm{VaR}$ over the long term. These results confirm the findings on terminal wealth distributions, suggesting that allocating to commodity-related investments reduce the extreme losses retirees may experience during their retirement.

Our findings present important implications to the pension funds management industry. The remainder of the paper proceeds as follows. Section 1 summarizes the relevant literature. Section 2 outlines data and investment strategies employed in this study. Section 3 discusses the detailed results and the paper concludes.

\section{Literature review}

Appropriate investment measures play a crucial role in wealth accumulation. In the retirement literature, existing research has mainly focussed on developing well-diversified and sustainable investment portfolios during the working life of individuals (Basu and Drew, 2009; Milevsky, 1998). Findings by Oeppen and Vaupel (2002) reveal that female life expectancy in the last 160 years has been increasing steadily by almost three months every year. Increasing life expectancy highlights the importance of optimal investment strategies and the need for adequate measures to cater for elongated retirement periods (Krumholz et al., 2015; Blake et al., 2006).

The literature reveals a number of key variables that determine retirement outcomes for the modern worker: contribution rate (Basu et al., 2011; Blake et al., 2001), risk aversion level (Jagannathan and Kocherlakota, 1996; Hickman et al., 2001) and gender (Neelakantan and Chang, 2010; Sunden and
Surette, 1998). Whilst the majority of the literature focuses on the accumulation phase, until recently, not much attention has been given to the decumulation phase. It is important in retirement that individuals take active measures to ensure that they do not outlive their available wealth. These include decisions regarding asset allocations, portfolio drawdown plans and longevity management. In many developed countries, the onus lies on the retiree to manage her risks in retirement, although there is the benefit of government sponsored pensions in countries such as Australia.

\section{Data and methodology}

For traditional asset classes, we obtain historical monthly returns data on U.S. equities and bonds between January 31, 1980 and May 31, 2014, spanning a period of 35 years sourced from the Global Financial Database (GFD). We employ the S\&P 500 Total Return Index as the equities investment and US 10-year Government Bonds Total Return Index as the proxy for bond investment.

For alternative investments, we employ the S\&PGSCI (Standard and Poor's Goldman Sachs Commodity Index) Total Return Index as a proxy for passive long-only commodities investing. The S\&P-GSCI consists of 24 actively traded commodities across energy (crude oil, brent, gas oil, natural gas, RBOB gas and heating oil), metals (aluminium, copper and zinc, lead, nickel, gold and silver), agriculture (Chicago wheat, Kansas wheat, corn, soybeans, cotton, sugar, coffee and cocoa) and livestock (live cattle, feeder cattle and lean hogs) sectors. The S\&P-GSCI is selected for two reasons. First, it is one of the most widely used performance benchmarks in commodity markets by industry practitioners. Second, a considerable number of exchange traded products on the S\&P-GSCI index are readily available.

Furthermore, the Barclay CTA (Commodity Trading Advisors) Index is employed as a proxy for commodity-related trend-following strategies. Published and maintained by Barclay Hedge, the Barclay CTA Index is computed based on of 535 trading programs. Only advisor which have four years or more of prior performance history are included in the index. Additional programs introduced by qualified advisors are not added to the Index until after their second year. The Barclay CTA Index is selected as it offers the longest history available for CTA performance tracking ${ }^{1}$. For both

\footnotetext{
${ }^{1}$ To eliminate survivorship bias, the Barclay CTA Index considers only CTAs with at least four years of performance history for inclusion in the index. Furthermore, the index avoids artificially inflated returns by ignoring the first four years of performance and only including managers' performance from year five onwards (see Darst, 2013).
} 
indices, we obtain daily closing prices from index inception dates through to July 31, 2014. Monthly returns are aggregated for the analysis. The data on S\&P-GSCI are available from December 31, 1969, whereas the Barclay CTA Index is available from January 31, 1980. Data on both indices are downloaded from DataStream International.

We use block bootstrap resampling to generate 20year return time series. This involves sampling one year blocks of consecutive values of the original returns time series, chosen randomly; with replacement. The blocks are placed one after the other to reproduce the 20-year time series. Since the return matrices hold rows of the different asset class returns, we are able to preserve the cross-correlation between the asset returns, as well as correlation within the various asset returns within each block.

A detailed explanation of the block bootstrap approach is presented in a seminal paper by Kunsch (1989). Recent use of this methodology in the retirement literature is by Basu et al. (2014). We repeat the procedure to construct 10,000 replica return time series. We assume the individual at age 65 years has $\$ 1,000$ of retirement savings from which she draws down for consumption over her remaining life. The level of drawdown is 4 per cent of initial wealth which is adjusted annually for inflation. The retiree allocates her wealth to a $60 / 40$ stock/bond portfolio; we refer to this as the traditional allocation. The portfolios are rebalanced

Panel A



annually to maintain the designated asset allocations. Retirees may also allocate some of their retirement wealth to alternatives by reducing their allocation to either equities or bonds. We allow allocation to alternatives of up to 20 per cent of total wealth over the decumulation phase. Our analysis is based on the first 20 years in retirement. We believe that important decisions such as those regarding agedcare, annuity purchase, as well as consumption levels may be made at this point in the postretirement phase.

\section{Empirical results}

Figure 1 shows the $5^{\text {th }}$ percentile of the distribution of terminal wealth for the different investment strategies after 20 years in retirement. Panel A reports the $5^{\text {th }}$ percentile of terminal wealth when 40 percent of assets are invested in bonds, and the remaining assets split between equities and alternatives. Different allocations to alternatives ranging from 5 percent to 20 percent replace stock in the investment portfolio. Panel $\mathrm{B}$ shows the allocation of alternatives replacing bonds, that is, 60 percent of assets are held in equities and the remaining split between bonds and alternatives for different proportions. The traditional asset allocation strategy is a $60 / 40$ split between equities and bonds with no alternative allocation ${ }^{2}$. The combined strategy has an equal weighted allocation to Commodities and CTA Index.

Panel B

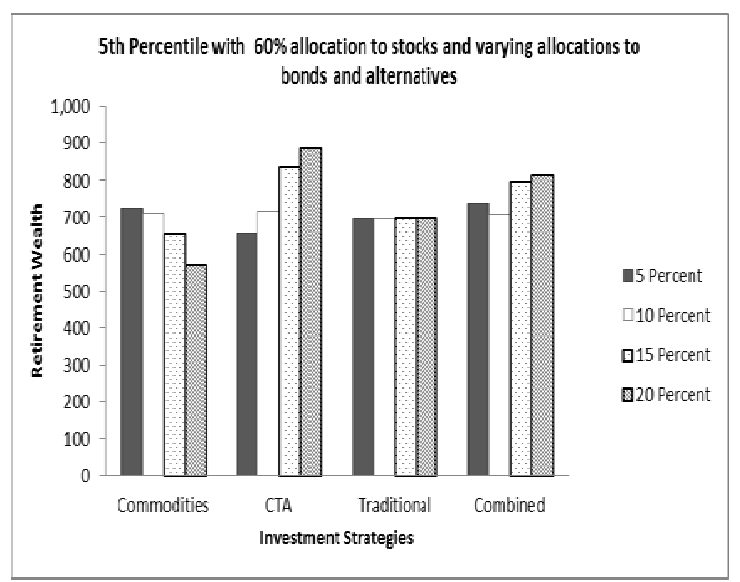

Fig. 1. Retirement terminal wealth at $5^{\text {th }}$ percentile

Two broad observations are made. Firstly, the retiree is better protected on the downside by reducing allocation to equities rather than bonds to invest in alternatives. This is explained by the high negative correlation between bonds and alternatives; this is significantly higher than the correlation relative to equities. The downside of terminal wealth is generally better for the reduced equity investor than the reduced bond investor. Secondly, there is a significant difference in the trend of portfolio allowing for different levels of alternative allocation.
Whilst increasing allocation to commodities generally decreases the fifth percentile of wealth, the inverse is reported for CTA, which requires active trading. An equally weighted combination of the two alternatives provides superior downside protection compared to a traditional portfolio at all levels of allocations used in the analysis. Differences

\footnotetext{
${ }^{2}$ For the traditional asset allocation, we plot the same wealth outcome separately to compare with the alternatives strategies at different allocation levels.
} 
between the different strategies with alternative allocations and the traditional portfolio are not significant at the fifth percentile.

Figure 2 shows the 1st percentile of the distribution of terminal wealth for the different investment strategies after 20 years in retirement. Panel A reports the 1st percentile of terminal wealth when 40 percent of assets are invested in bonds, and the remaining assets split between stock and alternatives. Different allocations to alternatives

Panel A

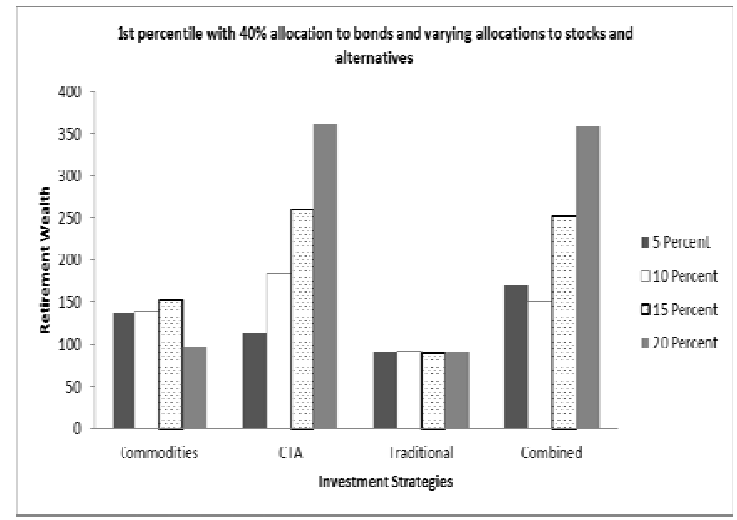

ranging from 5 percent to 20 percent replace stock in the investment portfolio. Panel B shows the allocation of alternatives replacing bonds, that is, 60 percent of assets are held in equities and the remaining split between bonds and alternatives for different proportions. The traditional asset allocation strategy is a $60 / 40$ split between equities and bonds with no alternative allocation. The combined strategy has an equal weighted allocation to Commodities and CTA Index.

Panel B

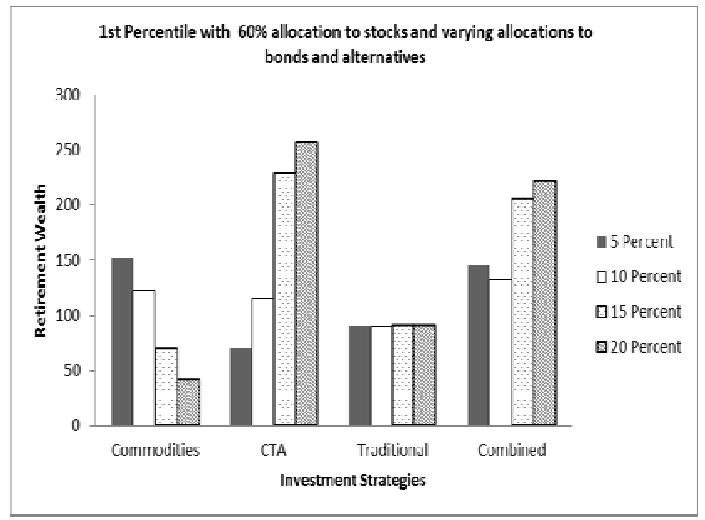

Fig. 2. Retirement terminal wealth at $1^{\text {st }}$ percentile

We report the $1^{\text {st }}$ percentile of terminal wealth from the total simulations in Panels A and B of Figure 2. Panel A shows the results of the terminal wealth percentile when asset allocation to alternatives replaces equities in the retirees portfolio, while Panel B shows the allocation of alternatives replacing bonds in the retiree's portfolio. The first percentile represents the worst case scenarios where the terminal wealth values lies in the lowest percentile of wealth. Having inadequate to sustain consumption is a significant risk in retirement. Basic finance theory postulates that diversifying a portfolio reduces idiosyncratic risk, and we expect the risk at the lowest percentile to be reduced with the inclusion of the additional asset class, as it is negatively correlated with both traditional assets.

Again, we find that the retirement portfolio performs better when allocation to alternatives replaces equities rather than bonds from the traditional portfolio allocation. Diversifying the portfolio by allocating a portion to alternatives provides a better downside, on average, compared to the traditional portfolio. Increasing asset allocation to commodities up to 15 percent; replacing equities in the retirement portfolio increases terminal wealth. Beyond this level of allocation, terminal wealth levels decrease. Even at 20 per cent, the first percentile of terminal wealth is higher for the portfolio with alternatives than the traditional portfolio. Terminal wealth at the first percentile increases with increasing allocation to CTA up to 20 percent. Even when allocation to alternatives is done with a reduction in bonds, there is still a significant increase in wealth levels with increasing proportion of allocation to CTA, while the inverse is noted for allocation to commodities. Commodities enhance the downside of terminal wealth for up to 10 per cent allocation and decrease wealth levels thereafter. An equally weighted allocation to the two alternative assets has a significant increase in downside wealth levels compared to the traditional approach.

Finally, we report the Expected Tail Loss (ETL) and Value-at-Risk (VaR) for the different investment strategies with 5 percent allocation to alternatives. These are two tail risk measures that estimate the worst outcomes for the different asset allocation strategies. The Value-at-Risk of a portfolio measures the potential loss in value of over a defined period for a given confidence interval. The Expected Tail Loss (ETL) provides the probability weighted average of investment portfolio outcomes that fall below the VaR at a given confidence interval. We estimate these risk measures over 5 year periods in the first 20 years in retirement. 
Panel A

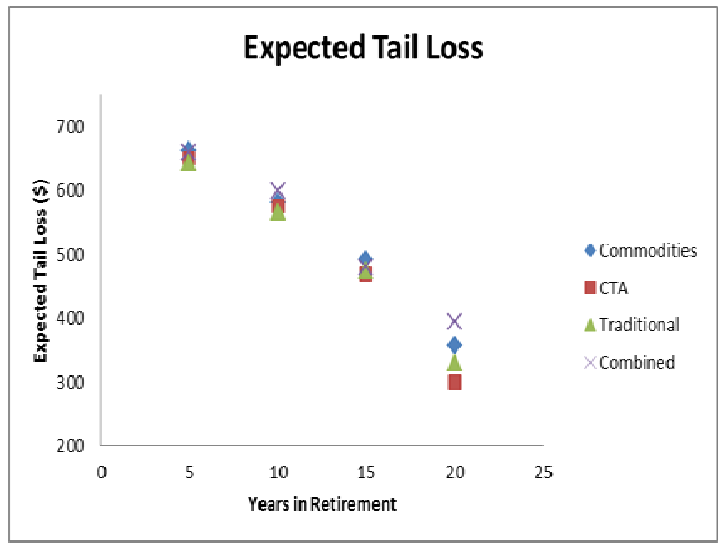

Panel B

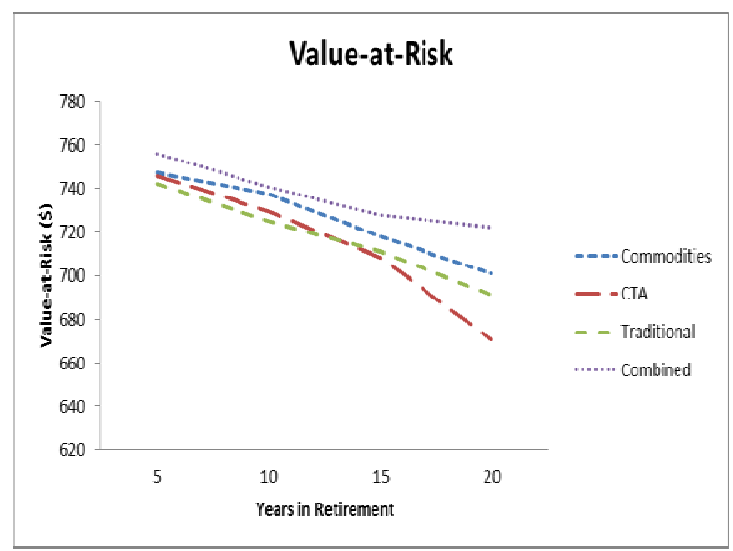

Fig. 3. Expected Tail Loss and Value-at-Risk over the retirement horizon

Figure 3 reports Expected Tail Loss and Value-atRisk estimates for the different investment strategies in the first 20 years in retirement at 5 year intervals. Value-at-Risk and Expected Tail Loss generally decrease with increasing investment horizon. While $\mathrm{VaR}$ is high early in retirement, variation in the VaR is lower between strategies, with all strategies generating substantial VaR levels in the first decade of retirement. Over time, as VaR reduces, it becomes more variable between strategies. After 20 years in retirement, retiree $\mathrm{VaR}$ is, on average, lowest for the strategy with allocation to CTA. This is evidence of a lower tail risk compared to the traditional asset allocation, although the latter has lower assets at risk than the strategy with a 5 percent allocation to commodities. The strategy with a combination of alternatives however underperforms the remaining strategies, having the highest VaR over the long term. Expected Tail Loss is lowest for the traditional asset allocation strategy in the first decade of retirement. It is outperformed by the strategy with allocation to CTA after 12 years. ETL for the combined alternatives strategy and the commodities strategy are higher than the traditional strategy throughout the first two decades of retirement.
The strategy with a 5 percent allocation to commodities, however, outperforms the combined alternatives strategy.

\section{Conclusion}

This study examines the role of commodity-related investments in the decumulation phase of retirement. We find that retirees are better protected on the downside in the decumulation phase by including commodity-related investments in their retirement portfolio. Furthermore, our findings suggest that downside protection is enhanced by reducing allocation to equities (rather than bonds) to invest in long-only commodities and CTA/Managed Futures. Further analysis using the Value-at-Risk and Expected Tail Loss measures reveal that an equally weighted combination of the passive and active commodity-related investments provides superior downside protection compared to a traditional portfolio at all levels of allocations used in the analysis. Overall, the findings presented in this paper suggest that commodity-related investments can be used as a diversification tool particularly in the decumulation phase of retirement portfolio.

\section{References}

1. Anson, M.J.P. (1999). Maximizing utility with commodity futures diversification, The Journal of Portfolio Management, 25 (4), pp. 86-94.

2. Basu, A.K., Chen, E.T. and Clements, A. (2014). Are lifecycle funds appropriate as default options in participantdirected retirement plans? Economics Letters, 124 (1), pp. 51-55.

3. Basu, A., Byrne, A. and Drew, M. (2011). Dynamic Lifecycle strategies for target date retirement funds, The Journal of Portfolio Management, 37(2), pp. 83-96.

4. Basu, A.K. and Drew, M.E. (2009). Portfolio Size and Lifecycle Asset Allocation in Pension Funds, Journal of Portfolio Management, 35(3), pp. 61-72.

5. Blake, D., Cairns, A.J. and Dowd, K. (2001). Pensionmetrics: stochastic pension plan design and value-at-risk during the accumulation phase, Insurance: Mathematics and Economics, 29(2), pp. 187-215.

6. Blake, D., Cairns, J. and Dowd, K. (2006). Living with mortality: Longevity bonds and other mortality-linked securities, British Actuarial Journal, 12(1), pp. 153-197.

7. Bodie, Z. and Rosansky, V.I. (1980). Risk and return in commodity futures, Financial Analysts Journal, 36(3), pp. 27-39.

8. Darst, David M. (2013). Portfolio Investment Opportunities in Managed Futures. New York: Wiley. 
9. Erb, C.B. and Harvey, C.R. (2006). The strategic and tactical value of commodity futures, Financial Analysts Journal, 62 (2), pp. 69-97.

10. Gorton, G. and Rouwenhorst, K.G. (2006). Facts and fantasies about commodity futures, Financial Analysts Journal, 62 (2), pp. 47-68.

11. Hickman, K., Hunter, H., Byrd, J., Beck, J. and Terpening, W. (2001). Life cycle investing, holding periods, and risk, The Journal of Portfolio Management, 27(2), pp. 101-111.

12. Hoevenaars, R.R., Molenaar, R., Schotman, P. and Steenkamp, T. (2008). Strategic Asset Allocation with Liabilities: Beyond Stocks and Bonds, Journal of Economic Dynamic and Control, 32, pp. 2939-2970.

13. Jagannathan, R. and Kocherlakota, N.R. (1996). Why should older people invest less in stocks than younger people? Federal Reserve Bank of Minneapolis Quarterly Review, 20, pp. 11-23.

14. Jensen, G.R., Johnson, R.R. and Mercer, J.M. (2002). Tactical asset allocation and commodity futures, The Journal of Portfolio Management, 28 (4), pp. 100-111.

15. Krumholz, H., Nuti, S., Downing, Normand, S. and Wang, Y. (2015). Mortality, Hospitalizations, and Expenditures for the Medicare Populations Aged 65 Years or Older, 1999-2013, Journal of the American Medical Association, 314(4), pp. 355-365.

16. Kunsch, H. R. (1989). The jackknife and the bootstrap for general stationary observations, The Annals of Statistics, pp. 1217-1241.

17. Milevsky, M.A. (1998). Optimal asset allocation towards the end of the life cycle: To annuitize or not to annuitize? Journal of Risk and Insurance, 65(3), pp. 401-426.

18. Neelakantan, U. and Chang, Y. (2010). Gender differences in wealth at retirement, American Economic Review, $100(2)$, pp. 362-367.

19. Oeppen, J., and Vaupel, J.W. (2002). Broken limits to life expectancy, Science, 296 (5570), pp. 1029-1031.

20. Sunden, A.E., and Surette, B.J. (1998). Gender differences in the allocation of assets in retirement savings plans, The American Economic Review, 88(2), pp. 207-211.

21. Van Rooij, M.C., Kool, C.J., and Prast, H.M. (2007). Risk-return preferences in the pension domain: are people able to choose? Journal of Public Economics, 91(3), pp. 701-722.

22. Wiafe, O.K. (2015). Investment Strategies in Retirees' Decumulation Phase. PhD thesis, Queensland University of Technology. 